\title{
Anti-fatigue action of peptides and amino acids derived from oyster on healthy subjects
}

\begin{abstract}
Objective: The aim of this study is to evaluate the effects of a supplement containing peptides and amino acids derived from oyster meat on fatigue of healthy individuals.

Methods: To a supplement-intake group, 201 subjects (average age, 35.3years old) were assigned, and they were orally administered the supplement containing peptides and free amino acids derived from oyster extract powder prepared by hydrolysis of oyster proteins for 4weeks. Fifty (50) subjects (average age, 34.9years old) were assigned to a control group which did not take the supplement. Fatigue feelings of the participants were examined by a questionnaire for fatigue feelings before and after the treatment. The intake period of 17 subjects in the supplement-intake group was extended by 12 weeks after obtaining their consent, followed by assessing the subjective fatigue feelings by the questionnaire and the objective fatigue levels by mechanical measurements.
\end{abstract}

Results: The fatigue feelings in the supplement-intake group evaluated by the questionnaire for work-related fatigue, were improved significantly after the treatment with the significant improvement of five factors of the fatigue feelings $(\mathrm{P}<0.01)$, while not in the control group. The fatigue feelings of the 17 subjects taking the supplement for 12 weeks evaluated by a visual analogue scale of fatigue level were improved significantly $(\mathrm{P}<0.05)$ and one of the indicator (saliva human herpes virus 6 [HHV-6]) of fatigue levels decreased significantly $(\mathrm{P}<0.01)$.

Conclusion: The oyster extract powder may improve fatigue to result in desired quality of life of healthy individuals.

Keywords:oyster, peptides/amino acids, fatigue, human herpes virus 6

\author{
Volume 2 Issue 2 - 2015
}

\author{
Taizo Seki,' Masahiko Ooe, ${ }^{2}$ Masaru Ohtani ${ }^{3}$ \\ 'Noevir Co, Ltd, Japan \\ ${ }^{2}$ Tokiwa Pharmaceutical Co, Ltd, Japan \\ ${ }^{3}$ Graduate of School of Frontier Sciences, The University of \\ Tokyo, Japan
}

\begin{abstract}
Correspondence: Masaru Ohtani,Visiting Professor, Sports Sciences for Health and Activity, Graduate School of Frontier Sciences, University of Tokyo Kashiwa Campus Environment Building No. 32I, 5-I-5 Kashiwanoha, Kashiwa-shi, Chiba-ken 277-8563, Japan, Tel I85 I 1905I, Fax 047|364644,

Email taizou_seki@nl.noevir.co.jp
\end{abstract}

Received: December 31, 2014 | Published: March 30, 2015

\section{Introduction}

Oyster (Crassostrea gigas) is one of the important aquatic resources for Japanese, and it has a long history as food. In terms of the quantity of production, Japan is the third, following China and Korea. ${ }^{1}$ As the oyster meat contains a plenty of nutrient components, it has been utilized as the health food in addition to food. Peptides contained in oyster meat extract powder have been paid attention as a functional constituent, and its efficacies on animal models with hypertension, hypercholesterolemia, and hyperglycemia are reported. ${ }^{2,3}$ In addition, there are several reports describing an anti-HIV effect of oyster meatderived peptides and effects of zinc contained in the oyster meat on dermatological symptoms including pruritus and acomia. ${ }^{4-6}$

It has been known that amino acids are useful from a nutritional view point for the recovery of physical fatigue in athletes. ${ }^{7,8}$ Blomstrand et al., ${ }^{9}$ suggest that branched-chain amino acids (valine, leucine, and isoleucine)can alleviate central fatigue, because these amino acids compete with tryptophan in the intake into the brain. A clinical study using a supplement containing a mixture of lysine and arginine demonstrates anti-stressand anti-anxiety effects of the mixture. ${ }^{10}$

A recent report by Tanaka et al., ${ }^{11}$ indicates an anti-fatigue effect of an imidazole peptide in which 2 amino acids bind together and which is contained in the protein resolvent of chicken and fish. This protein resolvent contains amino acids and peptides having an antioxidative effect and has been thought to contribute to the improvement of fatigue by suppressing the decrease of cell functions caused by an in vivo oxidative stress. There are few clinical assessment reports on the effects of oyster meat extract powder containing amino acids and peptides abundantly on the fatigue of healthy subjects. In this study, a supplement containing an oyster meat extract powder obtained by the enzyme hydrolysis was used and 251 healthy male and female adults were enrolled. In addition, 17 subjects among them were selected to conduct a test using a more detailed questionnaire, hematologic examination, and salivary test; and thereby the utility of the supplement was further validated.

\section{Materials and methods}

The study was reviewed and approved by the Ethical Review Board of Iryohojin Kenshinkai Shiromoto Clinic before starting the trials. A preliminary open label trial was carried out for a supplement-intake group from June to July 2012. A group not receiving the supplement was set during the same study period for comparison. In addition, the study was prolonged to total of 12 weeks until September 2012 for 17 subjects in the supplement-intake group after obtaining their consent.

\section{Test Supplement}

The oyster meat extract was prepared according to the procedure described by Tanaka et al., ${ }^{2}$ briefly after enzyme hydrolysis of oyster proteins contained in the oyster meat, the hydrolysate was concentrated and dried to obtain an oyster meat extract powder. The test supplement was a sugar coating tablet prepared by tableting this 
oyster meat extract powder in the pharmaceutical factory (Tokiwa Pharmaceutical Co., Ltd., Osaka, Japan) under Good Manufacturing

Practices. Table 1 gives blended constituents and nutrient components.

Table I Nutrient components and components derived from oyster meat extract powder obtained by enzyme hydrolysis in 12 test supplement tablets (sugarcoated tablet, $480 \mathrm{mg}$ each) for daily use, and distribution of peptide in oyster meat extract powder by enzyme hydrolysis ${ }^{23}$

\begin{tabular}{|c|c|c|}
\hline Item I & Item 2 & $\begin{array}{l}\text { Amount blended or } \\
\text { compositions }\end{array}$ \\
\hline \multirow{7}{*}{ Nutrient components in 12 test supplement tablets for daily use } & Energy & $21 \mathrm{kcal}$ \\
\hline & Protein & $\lg$ \\
\hline & Lipid & $0.1 \mathrm{~g}$ \\
\hline & Carbohydrate & $4 \mathrm{~g}$ \\
\hline & Sodium & $60 \mathrm{mg}$ or less \\
\hline & Zinc & $6.8 \mathrm{mg}$ \\
\hline & Glycogen & $624 \mathrm{mg}$ \\
\hline \multirow{6}{*}{$\begin{array}{l}\text { Components derived from oyster meat extract powder obtained by } \\
\text { enzyme hydrolysis in } 12 \text { test supplement tablets }\end{array}$} & $\begin{array}{l}\text { Oyster meat extract powder by } \\
\text { enzyme hydrolysis }\end{array}$ & $2,160 \mathrm{mg}$ \\
\hline & Peptide & $648 \mathrm{mg}$ \\
\hline & Amount of valyltyrosine in peptide & $0.44 \mathrm{mg}$ \\
\hline & Free amino acid & $132 \mathrm{mg}$ \\
\hline & Taurine & $80 \mathrm{mg}$ \\
\hline & Others, glucose, ash content, water & I,300mg \\
\hline \multirow{5}{*}{$\begin{array}{l}\text { Distribution of peptide in oyster meat extract powder by enzyme } \\
\text { hydrolysis }(\mathrm{Da})\end{array}$} & 500 or less & $73 \%$ \\
\hline & $500-1000$ & $15 \%$ \\
\hline & $1000-3000$ & $11 \%$ \\
\hline & $3000-6000$ & $1 \%$ \\
\hline & 6000 or less & $0 \%$ \\
\hline
\end{tabular}

The test sample tablet contains granulated sugar, lactose, yeast extract containing cysteine peptides, zinc yeast powder, refined processing fat for food, crystalline cellulose, thickener (gum arabic, gelatine), calcium stearate, talc, shellac, calcium carbonate, artificial color (caramel, carminic acid), propylene glycol, and carnauba wax in addition to oyster meat extract powder

\section{Subjects, intake of test supplement and intake period}

The subjects were to be 251 healthy male and female adults who lived in the same region. In the intake group, 201 subjects (average age: $35.3 \pm 0.7$ years old, 148 males, 53 females) were allocated, while 50 subjects (average age: $34.9 \pm 1.5$ years old, 36 males, 14 females) allocated in the non-intake group. The 201 subjects in the intake group took 12 supplement tablets containing the oyster meat extract powder every day in addition to the usual diet, while the subjects in the non-intake group lived usual life. The study period was to be 4weeks, fatigue of each subject was assessed by using a questionnaire for work-related fatigue, which has been established as the name of "Jikaku-sho shirabe" by Working Group for Occupational Fatigue in Japan Society of Occupational Health before and after the present study. ${ }^{12}$

From 201 subjects in the intake group, 40 subjects were selected in order of decreasing age. After 20 subjects were randomly selected from the 40 subjects, we asked for the thought of the selected subjects about continuous intake of the supplement blending the oyster meat extract powder. Then, the supplement blended with oyster meat extract powder was continuously given for 12 weeks to 17 male subjects (average age $42.1 \pm 1.2$ years old) who agreed the continuous intake, and the subjective fatigue was additionally assessed before and after the study by using Visual Analogue Scale (VAS) method ${ }^{13,14}$ established by Japanese Society of Fatigue Science and Chalder's fatigue scale ${ }^{15}$ in addition to the questionnaire for work-related fatigue. In addition to the above-mentioned questionnaire, blood and salivary tests were conducted as the evaluation of objective fatigue level.

\section{Questionnaire}

The questionnaire for work-related fatigue contains 5 questions. Each question consists of 5 items of feeling of sleepiness, feeling of unsteadiness, sense of discomfort, feeling of tiredness, and blurred feeling, and self-assessment is performed with 5 steps. The questionnaire is given to subjects as a survey slip for the subjective fatigue assessment by which we can calculate fatigue scores with full score of 125 for totaling 25 items. The VAS method that has been recommended by Japanese Society of Fatigue Sciences a method to allow a self-evaluation of the present subjective fatigue by using a 10 -cm line segment on which "the most not-tired state" is assumed 
to be located in the left end point and "the most tired state" in the right end point. ${ }^{13,14}$ Chalder's fatigue scale is a survey slip to assess the subjective fatigue based on the total scores obtained by selfassessment by answering questions of 14 items with 4 steps. ${ }^{15}$

\section{Blood index}

From 17 subjects from whom consent was obtained, blood was withdrawn under fasting condition in the early morning 3 times just prior to the start of the study, onweek 4 andweek 12 from the study initiation. By using the blood specimens, blood markers including AST, ALT, $\gamma$-GT, LDL-C (LDLcholesterol), HDL-C (HDL cholesterol), total cholesterol, TG (triglyceride), total protein, albumin, CRE (creatinine), uric acid, urea nitrogen, and cortisol were examined. Among blood lipid markers, LDL-C, HDL-C, total cholesterol, and TG were measured by the enzyme methods in a measurement institution (Mitsubishi Chemical Medience Corporation, Tokyo, Japan).

\section{Salivary examination}

From 17 subjects from whom consent was obtained, salivary was collected 3 times just prior to the start of the study, on week 4 and week 12 from the study initiation. By using commercially available measuring kit (Quantification of Human Herpes Virus 6 Standard kit and Precision qPCR Master Mix, Primer Design Ltd, Southampton, UK), DNA quantity of salivary human herpes virus 6 (HHV-6: Human Herpes Virus 6) was quantitated by the real time PCR method. ${ }^{16}$ In addition, the amount of salivary cortisol which is a stress index was quantitatively analyzed by using a commercially available measuring kit (Cortisol EIA kit, Salimetrics, LLC Carlsbad, USA). ${ }^{17}$

\section{Autonomic nerve measurement}

For 17 subjects from whom consent was obtained, the autonomy neurologic function was measured 3times just prior to the start of the study, on week 4 and week 12 at the completion with an acceleration pulse wave measurement system, Artett C, Umedica Laboratories, Pvt. Ltd., Mumbai, India). The measurement time was to be $2.5 \mathrm{~min}$. This measurement instrument quantifies 0.02 to $0.15 \mathrm{~Hz}$ as the lowfrequency wave constituent (LF: low frequency) mainly reflecting the sympathetic nerve and $0.15 \mathrm{~Hz}$ to $0.50 \mathrm{~Hz}$ as the high-frequency wave constituent (HF: high frequency) reflecting the parasympathetic nerve. This time, as the autonomy neurologic function, the ratios of the low-frequency wave constituent to the high-frequency wave constituent ( $\mathrm{LF} / \mathrm{HF}$ ratio) were used for an analysis.

\section{Statistical analysis methods and description methods of numeral values}

The statistical analysis was carried out by using SPSS Statistics 12. Wilcoxon signed-rank test was performed in the comparison of aggregate calculation results of the questionnaires in the supplementintake group before initiation of the study and 4weeks after the study start. Mann-Whitney $U$ test was used in the comparison of the aggregate calculation results of the questionnaires between the supplement-intake group and the non-intake group. Before the initiation of study, and on week 4 and week 12 after the initiation of intake, the measurement values of the questionnaire for workrelated fatigue, fatigue VAS, Chalder's fatigue scale, autonomic nerve balance (LF/HF ratio), and salivary HHV-6, all of which were determined in the 17 subjects who took the supplement for 12 weeks, were compared by Friedman test. For other quantitative data, the repeated measurement analysis of variance was applied. We judged that there was a significant difference in case where the significant level was less than $5 \%$, and that there was a tendency in case of less than $10 \%$. The numeral values are represented as $\mathrm{SEM} \pm$ Mean.

\section{Results}

\section{Subject characteristics}

The characteristics of all the subjects at the time of study start are shown in Table 2. Before the initiation of study, a mean score of the feeling of fatigue in all the subjects examined by the questionnaire for work-related fatigue was 50.4 and that of the subjects in the nonintake group before the initiation of study was 56.6. These scores indicated low fatigue level of the subjects in both groups and there was no significant difference in the feeling of fatigue at the starting time between the supplement-intake group and the non-intake group. In addition, Table 2 represents the characteristics of the 17 subjects who were selected so as to prolong their study period for 12 weeks from the supplement-intake group. The mean score of feeling of fatigue of the 17 subjects was 52.8 points before the initiation of the study, and there was no large difference from the mean values of all the subjects.

Table 2 Subject profiles at the time of study initiation (Mean \pm SEM)

\begin{tabular}{|c|c|c|c|}
\hline & $\begin{array}{l}\text { Supplement } \\
\text { intake group } \\
(n=201)\end{array}$ & $\begin{array}{l}\text { Supplement non-intake group } \\
(n=50)\end{array}$ & $P$ value \\
\hline Age (year) & $35.3 \pm 0.7$ & $34.9 \pm 1.5$ & 0.83 \\
\hline Male (No.) & 148 & 36 & - \\
\hline Female (No.) & 53 & 14 & - \\
\hline $\begin{array}{l}\text { Score of the } \\
\text { questionnaire } \\
\text { for work-related } \\
\text { fatigue }\end{array}$ & $50.4 \pm 1.1$ & $56.6 \pm 2.9$ & 0.087 \\
\hline
\end{tabular}

Table 2A Four-week intake study (Mann-Whitney U-test)

Table 2B Twelve-week intake study

\begin{tabular}{|c|c|}
\hline & $\begin{array}{l}\text { Supplement intake group for } 12 \text { weeks } \\
(n=\mid 7)\end{array}$ \\
\hline Age (year) & $42.1 \pm 1.2$ \\
\hline Male (No.) & 17 \\
\hline $\begin{array}{l}\text { Score of the questionnaire } \\
\text { for work-related fatigue }\end{array}$ & $52.8 \pm 1.8$ \\
\hline
\end{tabular}

\section{Questionnaire}

The aggregate calculation results of the questionnaire for workrelated fatigue obtained from all the subjects on week 4 of the study period are shown in Figure 1. The subjects in the supplement-intake group showed significant improvement of the feeling of fatigue after the study in comparison with that before the study initiation $(\mathrm{P}<0.01)$. Figure 2 depicts the analysis results by item in the questionnaire for work-related fatigue. In the supplement-intake group, the total scores of 5 items of feeling of sleepiness, feeling of unsteadiness, sense of discomfort, feeling of tiredness, blurred feeling were significantly decreased on week 4 in comparison with those before the study initiation $(\mathrm{P}<0.01$ for all the items). In addition, the comparison between the non-intake group and the intake group confirms significant decrease of the feeling of fatigue in the supplement-intake group $(\mathrm{P}<0.01)$. 


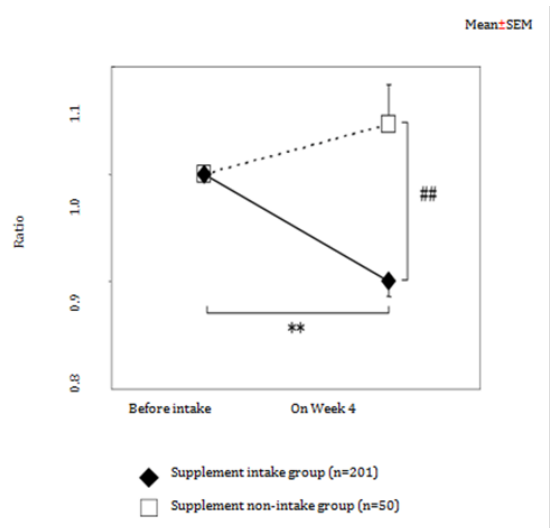

Figure I Comparison of scores between supplement intake group $(n=20$ I) and non-intake group $(n=50)$ on Week 4 determined by the questionnaire for work-related fatigue.

Comparison with the score at the initiation

of intake: $* * \mathrm{P}<0.01$, Wilcoxon signed-rank test.

Comparison with the score of non-intake group: \# P<0.0I, Mann-Whitney $U$ test.

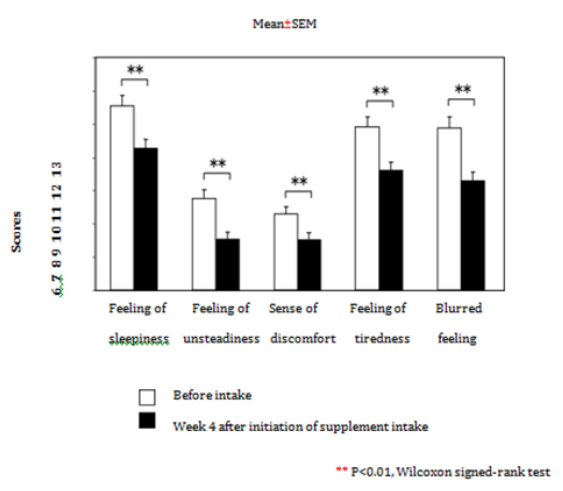

Figure 2 Change of range of scores by scale in the questionnaire for workrelated fatigue $(n=201)$ before intake of supplement blended with oyster meat extract powder and on Week 4 of it intake.

The feeling of fatigue of the 17 subjects whose study period was prolonged by 12 weeks was assessed by the VAS method and significantly decreased at the study completion $(\mathrm{P}=0.01$, Figure 3$)$. The improvement tendency of the feeling of fatigue was demonstrated by the questionnaire for work-related fatigue ( $\mathrm{P}=0.08$, Figure 4$)$. In addition, the assessment of feeling of fatigue by using Chalder's fatigue scale indicated improvement tendency onweek 12 in comparison with that before the study initiation ( $\mathrm{P}=0.09$, Figure 5).

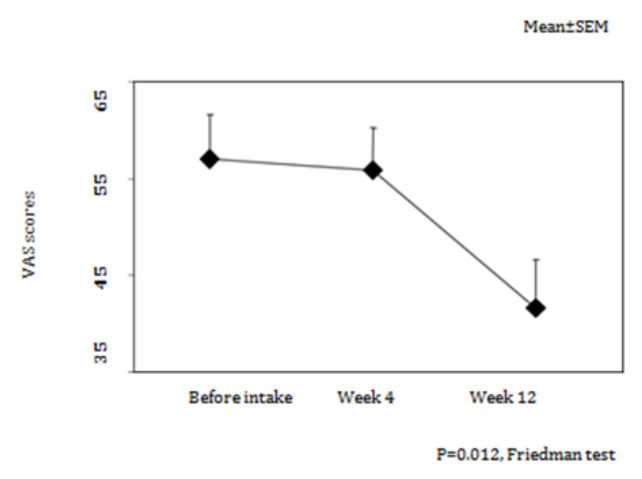

Figure 3 Change of fatigue VAS $(n=17)$ by intake of supplement blended with oyster meat extract powder in the I 2 week continuous intake study.

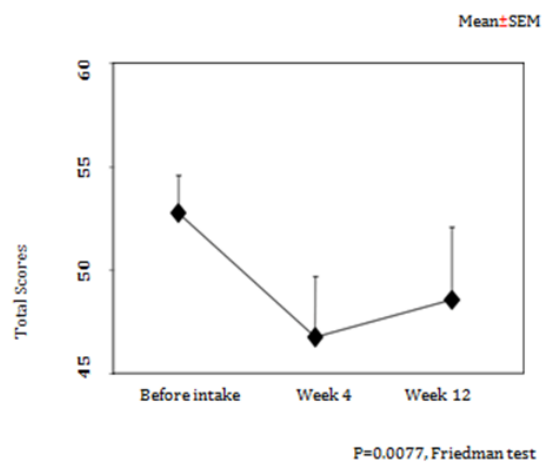

Figure 4 Change of total scores determined by the questionnaire for workrelated fatigue in 17 subjects who took supplement blended with oyster meat extract powder continuously for 12 weeks.

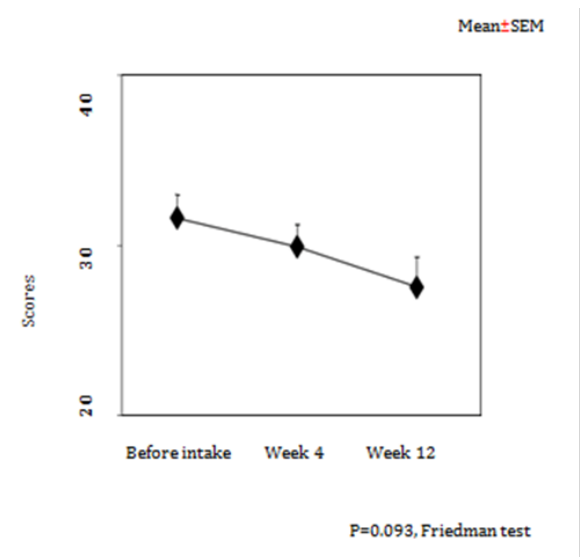

Figure 5 Change of Chalder's fatigue scale in 17 subjects who took supplement blended with oyster meat extract powder continuously for 12 weeks.

\section{Blood index and salivary index}

Table 3 indicates blood index values and salivary index values during the study period of the 17 subjects whose study period was prolonged by 12 weeks. The mean values of blood index changed within the range of healthy subjects. Significant changes were observed in HDL-C, total cholesterol, total protein, albumin, CRE, and cortisol, but any of the variations were slight, and deviation from the standard range was not observed in any parameters. As shown in Figure 6 , the results of salivary test show a significant decrease of the salivary HHV-6 value onweek $12(\mathrm{P}<0.01)$. There was no change in the quantity of salivary cortisol which is a stress index (Table 3 ).

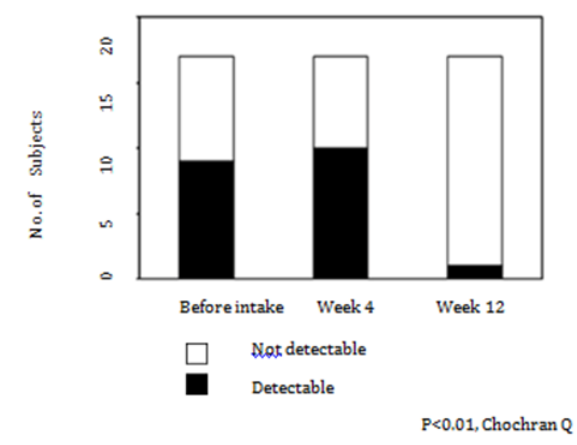

Figure 6 Change of reactivation of salivary HHV-6 in 17 subjects who took supplement blended with oyster meat extract powder continuously for I2weeks. 
Table 3 Change of each parameter in hematologic examination and salivary test, and autonomy neurologic function in the 17 subjects who took supplement blended with oyster meat extract powder continuously I 2 weeks (Mean \pm SEM)

\begin{tabular}{|c|c|c|c|c|c|c|}
\hline Parameter & Unit & Standardvalue & Before intake & Week 4 & Week I 2 & $P$ value \\
\hline \multicolumn{7}{|c|}{ Hematologic exam } \\
\hline HDL-C & $\mathrm{mg} / \mathrm{dL}$ & $40-85$ & $56.4 \pm 2.9$ & $50 \pm 2.8$ & $52.4 \pm 2.6$ & $<0.01 * *$ \\
\hline LDL-C & $\mathrm{mg} / \mathrm{dL}$ & $65-139$ & $124.5 \pm 7.3$ & $116.9 \pm 5.3$ & $118.7 \pm 6.3$ & 0.09 \\
\hline Total C. & $\mathrm{mg} / \mathrm{dL}$ & $120-219$ & $198.6 \pm 6.7$ & $192.2 \pm 5.2$ & $188.6 \pm 6.2$ & $0.03 *$ \\
\hline TG & $\mathrm{mg} / \mathrm{dL}$ & $30-149$ & $91 \pm 9.7$ & $114.8 \pm 17.6$ & $94.9 \pm 12.2$ & 0.07 \\
\hline Cortisol & $\mu g / d L$ & $4.0-19.3$ & $8.21 \pm 0.6$ & $9.82 \pm 0.6$ & $10.93 \pm 0.5$ & $<0.01$ \\
\hline AST & IU/L & Oct-40 & $23.9 \pm 2.4$ & $22.6 \pm 1.8$ & $23.1 \pm 2.2$ & 0.27 \\
\hline ALT & $\mathrm{IU} / \mathrm{L}$ & May-45 & $28.6 \pm 5.3$ & $26.9 \pm 4.5$ & $26.9 \pm 4.6$ & 0.34 \\
\hline$\gamma-\mathrm{GT}$ & $\mathrm{IU} / \mathrm{L}$ & $\leq 80$ & $52.4 \pm 15.1$ & $47.9 \pm 13$ & $48.8 \pm 14.0$ & 0.1 \\
\hline Total protein & $\mathrm{g} / \mathrm{dL}$ & $6.7-8.3$ & $7.35 \pm 0.1$ & $7.09 \pm 0.1$ & $7.1 \pm 0.1$ & $<0.01 * *$ \\
\hline Albumin & $\mathrm{g} / \mathrm{dL}$ & $3.8-5.3$ & $4.7 \pm 0.0$ & $4.5 I \pm 0.1$ & $4.56 \pm 0.0$ & $<0.01 * *$ \\
\hline Creatinine & $\mathrm{mg} / \mathrm{dL}$ & $0.61-1.04$ & $0.87 \pm 0.02$ & $0.85 \pm 0.02$ & $0.89 \pm 0.02$ & 0.03 \\
\hline Uric acid & $\mathrm{mg} / \mathrm{dL}$ & $3.8-7.0$ & $6.04 \pm 0.3$ & $6.07 \pm 0.3$ & $6.07 \pm 0.3$ & 0.95 \\
\hline BUN & $\mathrm{mg} / \mathrm{dL}$ & 20-Aug & $12.6 \pm 0.5$ & $12.6 \pm 0.6$ & $13.2 \pm 0.6$ & 0.38 \\
\hline \multicolumn{7}{|l|}{ Salivary test } \\
\hline Cortisol & $\mathrm{pmol} / \mathrm{mL}$ & - & $7.57 \pm 1.0$ & $8.93 \pm 1.5$ & $7.8 I \pm 0.6$ & 0.5 \\
\hline \multicolumn{7}{|c|}{ Autonomy neurologic function } \\
\hline $\mathrm{LF} / \mathrm{HF}$ & - & $\leq 2.0$ & $1.6 \pm 0.3$ & $1.36 \pm 0.2$ & $1.56 \pm 0.3$ & 0.34 \\
\hline
\end{tabular}

Repeated measurement analysis of variance for each parameter, and Friedman test for autonomic nerve

*,P<0.05; **, P<0.0I;ALT, alanine aminotransferase;AST, aspartate aminotransferase; $\Gamma$-GT, $\gamma$-glutamyl transpeptidase; HDL-C, high density lipoprotein cholesterol; LDL, low density lipoprotein; LDL-C, low density lipoprotein cholesterol; TG, triglyceride; SEM, standard error of mean

\section{Measurement of autonomic nerve}

Table 3 shows the autonomy neurologic function during the study period of the 17 subjects whose study period was prolonged by 12 weeks. No large changes were observed in the LF/HF ratio before and after the implementation of the study.

\section{Adverse events and adverse drug reactions}

All the subjects completed the study, and the hematologic examination and the hearing investigation confirm no appearance of adverse events that have causal relationship with the intake of the test supplement.

\section{Limitation of this research}

Since this study compared the supplement-intake group with the non-intake group as the preliminary open-labeled study, a placebo effect cannot be particularly denied in the assessment of fatigue by using the questionnaire. In addition, since the subject of this study belonged to a population group in which employment status and regular exercise of each subject were not the same though they lived in the same region, there is concern about a point varying in the fatigue level that can accumulate in their daily life. From the view points of these limitations, it is required to carefully review the results obtained, and the implementation of a double blind placebo comparison study or an individual (N-of-1) trial ${ }^{18}$ is thought to be our next task.

\section{Discussion}

The average score of the feeling of fatigue in the 201 healthy male and female adult subjects determined by the questionnaire for workrelated fatigue was 50.4 points before the initiation of the study. Since the score is 125 when subjects are most tired, the feeling of fatigue of the present subjects before the initiation of the study was unlikely to be diseased fatigue. The 4 week intake of said supplement significantly improved the feeling of fatigue in the questionnaire for work-related fatigue and in the analysis results by scale for all of the 5 items. In addition, the comparison with the non-intake group demonstrates the significant improvement of the rate of change for the feeling of 
fatigue in the intake group at the completion time of the study. The oyster meat extract powder may affect the systemic homeostasis, and thereby mild fatigue which healthy adults usually feel was reduced.

Then, we had 17 subjects allocated in the intake group take the supplement continuously for 12 weeks and performed detailed measurement by using fatigue VAS, the questionnaire for workrelated fatigue, and salivary HHV-6 as the indices of usual daily fatigue. The questionnaires of the fatigue VAS and the questionnaire for work-related fatigue have been used for the assessment of shortterm fatigue. ${ }^{12,19}$ The intake of the oyster meat extract powder caused the significant decrease of fatigue VAS and the decreasing tendency in the questionnaire for work-related fatigue; the results suggesting the contribution of the oyster meat extract powder to the improvement of daily life fatigue. Eight types of human HHV have been hitherto discovered. Any of HHV has characteristics that they proliferate to certain quantity at the time of initial infection, followed by terminating the proliferation, and the latent state under which the virus gene is maintained continues throughout the life of host. ${ }^{20} \mathrm{HHV}-6$ is a virus with which most of people have been first infected at 1.5 years old, causes sudden rash during babyhood stage, and its participation in drug-induced hypersensitivity syndromes has been known. ${ }^{16,21}$

In recent years, studies on the relation of HHV-6 with fatigue have advanced and the followings have been elucidated:

i. Stress with long term tasks re-activates salivaryHHV-6 in healthy volunteers,

ii. the activation is reported to be suppressed by taking rest, and

iii. The re-activation is likely to be induced by the excessive formation of cytokines. ${ }^{16}$

In this study, re-activation of salivary HHV-6 was observed in 9 of 17 subjects before the supplement intake, and the salivary HHV-6 was decreased to less than the detection limit after intake of the oyster meat extract powder other than 1 subject. The results and discussion described above indicate that the intake of oyster meat extract powder probably reduced the objective fatigue levels and subjective fatigue feeling in the healthy adults who accumulate usual fatigue through the inhibition of re-activation of viruses by controlling the generation of cytokines.

Chronic fatigue syndrome (CFS) is a disease by which strong fatigue is felt for a halfyear or longer without any obvious reasons, and the cause of CFS has been unknown even now. The decrease of the homeostasis of immune system induced by various kinds of environmental factors (physical and psychological stress) and genetic factors is proposed for the mechanism of onset of CFS as a hypothesis. ${ }^{22}$ Chalder's fatigue scale and the autonomy neurologic functions were used as the indices of CFSi n this study. Chalder's fatigue scale is a questionnaire recommended for diagnosis of fatigues including CFS by U.S. Centers for Disease Control and Prevention. CFS patients are reported to show significantly higher LF/HF ratio than healthy subjects. ${ }^{21}$ The intake of the present supplement caused a tendency of decrease of Chalder's fatigue scale, but the change was not large. No change was observed in the LF/HF ratio. Since the subject in this study was the healthy adults, a large difference was unlikely to be observed in these indices. The effect of oyster meat extract powder on CFS was unable to be assessed, because no CFS patient was included in the subjects in this study; thus, we think that the implementation of a study on CFS patients is essential.

Tanaka et al., ${ }^{2}$ report that the oyster meat extract powder used in this study decreased fatty acid synthase (FAS) activity and the amount of triglyceride (TG) in the liver in Sprague-Dawley rats. In addition, a clinical study on hyperlipidemia patients who took the oyster meat extract powder indicates the possibilities of the normalization of blood lipid levels and the activation of body protein synthesis. ${ }^{23}$ As one of the mechanisms by which fatigue is prolonged, the contribution of decrease in functions of the liver and other organs is suggested; thus, by the function reduction, energy metabolism in organs including the liver does not advance smoothly, the lack of energy occurs in a body, and thereby the restoration of cell functions and new protein synthesis are inhibited. ${ }^{24}$ Based on these results, the decrease of fatigue confirmed in this study is probably attributable to the stimulation of energy metabolism and body protein synthesis by the intake of the oyster meat extract powder.

The oyster meat extract powder used in this study contains valyltyrosine which inhibits angiotensin-converting enzyme I and has the activity of hypertension prevention. ${ }^{25}$ It is known that valyltyrosine is contained in sardine peptides derived from sardine proteins, and supplements blended with the sardine peptides has been accredited as a food for specified health use for "the person whose blood pressure is somewhat high" by Ministry of Health, Labour and Welfare. Any of the accredited commercial products contains valyltyrosine at $0.4 \mathrm{mg}$ for daily use, and since the present supplement contains $0.44 \mathrm{mg} /$ day of valyltyrosine, hypotensive effect could be predicted. However, no decrease of blood pressure was observed in this study (data not shown) probably because of the small number of subjects with hypertension. At the time of study initiation, 5 of mild17 subjects suffered from mild hypertension, but remaining 12 subjects showed normal blood pressure. The blood pressure of the 5 subjects was decreased, though a significant difference was not observed. The mean blood pressures in the 5 subjects were as follows. Systolic blood pressures were $152.0 \pm 4.6 \mathrm{~mm} \mathrm{Hg}$ on week $0,142.3 \pm 9.6 \mathrm{~mm} \mathrm{Hg}$ on week 4 , and $141.5 \pm 8.1 \mathrm{~mm} \mathrm{Hg}$ on week 12 , while diastolic blood pressures were $96.5 \pm 4.4 \mathrm{~mm} \mathrm{Hg}$ on week $0,92.0 \pm 5.2 \mathrm{~mm} \mathrm{Hg}$ onweek 4, and $92.5 \pm 7.5 \mathrm{~mm} \mathrm{Hg}$ on week 12. On the other hand, since no large change in the blood pressure was observed in the remaining 12 subjects (data not shown), a safety of the supplement blended with oyster meat extract powder was suggested.

The results described above indicate the intake of peptides and amino acids derived from oyster is likely to reduce mild fatigue felt by healthy adults in everyday life and to contribute to QOL improvement. The marine creature wealth containing various nutrients such as DHA lipids, chitin polysaccharides, amino acids and peptides will be utilized increasingly as the important materials for healthcare. ${ }^{26,27}$ The next our task is to identify the functional amino acids and peptides contained in the oyster extract powder, to elucidate a detailed action mechanism(s), and to explore the new utility of the oyster extract powder in the prevention of life style related diseases.

\section{Acknowledgements}

The authors thank Prof. Akiyoshi Takada in Graduate School of Medicine, Osaka University for his suggestion and advice. We are also indebted to Mr. Takuya Yabu-uchi for the study instruction. We appreciate the help by Mr. /Ms. Hidenobu Okumura, Seiji Kurita, Hiroshi Matsui, Fumie Takamatsu, and Yayoi Kurokawa with their assistance in this study and valuable discussion. Some contents of this article was presented in the 35th Annual Meeting of Japanese Society of Clinical Nutrition (2013, Kyoto).

\section{Conflict of interest}

Author declares that there is no conflict of interest. 


\section{References}

1. Statistical Survey Department. Statistics Bureau of Ministry of Agriculture, Forestry and Fisheries. 2012 Statistics on Fishery and Aquaculture Production. 2013.

2. Tanaka K, Nishizono S, Kugino K, et al. Effects of dietary oyster extract on lipid metabolism, blood pressure, and blood glucose in SD rats, hypertensive rats, and diabetic rats. Biosci Biotechnol Biochem. 2006;70(2):462-470.

3. Shiozaki K, Shiozaki M, Masuda J, et al. Identification of oyster-derived hypotensive peptide acting as angiotensin I converting enzyme inhibitor. Fish Sci. 2010;76:865-872.

4. Lee TG, Maruyama S. Isolation of HIV-1 protease-inhibiting peptides from thermolysin hydrolysate of oyster proteins. Biochem Biophys Res Commun. 1998;253(3):604-608.

5. Yamanaka T, Taguchi S, Ishihara S, et al. The anti-pruritic effects of oyster extract. J Tokyo Med Univ. 2007;65:393-400.

6. Tazaki M, Matsumura K, Hanada M. A therapy experience of alopecia by oyster meat extract formulation. The Clinical Report. 1985;19:2295-2304.

7. Sugita M, Ohtani M, Ishii N, et al. Effect of a selected amino acid mixture on the recovery from muscle fatigue during and after eccentric contraction exercise training. Biosci Biotecnol Biotechnol Biochem. 2003;67(2):372-375.

8. Ohtani M, Sugita M, Maruyama K. Amino acid mixture improves training efficiency in athletes. J Nutr. 2006;136(2):538S-543S.

9. Blomstrand E, Hassmen P, Ek S, et al. Influence of ingesting a solution of branched-chain amino acids on perceived exertion during exercise. Acta Physiol Scand. 1997;159(1):41-49.

10. Smriga M, Ando T, Akutsu M, et al. Oral treatment with L-lysine and L-arginine reduces anxiety and basal cortisol levels in healthy humans. Biomed Res. 2007;28(2):85-90.

11. Tanaka M, Shigihara Y, Fuzii H, et al. Effect of CBEX - Dr - containing Drink on Physical Fatigue in Healthy Volunteers. Jpn Pharmacol Ther. 2008;36(3):199-212.

12. Itani T. Application method of a new version of "Jikaku-sho shirabe". Digest of Science of Labour. 2002;57:37-40.

13. Lee KA, Hicks G, Nino-Murcia G. Validity and reliability of a scale to assess fatigue. Psychiatry Res. 1991;36(3):291-298.

14. Tanaka M, Mizuno K, Yamaguti K, et al. Autonomic nervous alterations associated with daily level of fatigue. Behav Brain Funct. 2011;7:46-51.
15. Chalder T, Berelowitz G, Pawlikowska T, et al. Development of a fatigue scale. J Psychosom Res. 1993;37(2):147-153.

16. Kondo K. Human herpesvirus latency and fatigue. Uirusu. 2005;55(1):9-17.

17. Nomura S, Mizuno T, Nozawa A, et al. Physiological assessment of mild mental work load by salivary cortisol. Jpn J Biofeedback Res. 2009;36:23-32.

18. Zucker DR, Ruthazer R, Schmid CH. Individual (N-of-1) trials can be combined to give population comparative treatment effect estimates: Methodologic considerations. J Clin Epidemiol. 2010;63(12):1312-1323.

19. Shimizu K, Fukuda M, Yamamoto H.m Usefulness of continuous intake of beverage blended with imidazole dipeptides in healthy subjects who realize fatigue in usual working - An analysis result report of 207 subjects with the first entry. Jpn Pharmacol Ther. 2009;37(3):255-263.

20. Kuratsune H, Yamaguchi K, Sasabe T. Autonomy neurologic function assessment chronic fatiguesyndrome patient (Ministry of Welfare). Final report of research fiscal year. 2010.

21. Hashimoto K. Drug-induced hypersensitivity syndrome and human herpesvirus 6. Modern Media. 2010;56:305-310.

22. Kuratsune $\mathrm{H}$. To what extent do we understand chronic fatiguesyndrome? In: Watanabe Y, editor. Most up-to-date science of fatigue Recommendation to anti-fatigue and anti-over fatigue from Japan. Ishiyaku Publishers; 2010:91-98.

23. Ohtani M, Seki T, Ooe M, et al. Effects of Peptides and Amino Acids Derived from Oyster on Blood Lipids. J Nutr Health Food Eng. 2014;1(5):00027.

24. Watanabe Y. Mechanism of fatigue -The hypotheses up to now and the present hypotheses. In: Watanabe Y, editor. Most up-to-date science of fatigue- Recommendation to anti-fatigue and anti-over fatigue from Japan. Ishiyaku Publishers; 2010:10-16.

25. Matsui T, Kawasaki S. The hypotension effects of functional peptides derived from food proteins: Focusing on the development of foods for hypotension derived from sardine peptide (Var-Tyr). J Jap Soc Nutr Food Sci. 2000;53:77-85.

26. Ohtani M, Itoh Y, Okamoto Y. Primary dementia prevention and nutritional effects of long-term supplementation with docosahexaenoic acid, gingko biloba, and amino acids on forgetfulness of middle-aged people. J Jap Soc Clin Nutr (Japanese article). 2012;34(4):151-157.

27. Seki T, Ohtani M, Aoi K. Development of an amphiphilic chitin derivative with lipid/peptide-type side chains having skin protective ability. J Nutr Health Food Eng. 2015. 